\title{
Cisplatin Induced Histological and Ultrastructural Alterations In Liver Tissue of Rat
}

\author{
Pratibha R Kamble ${ }^{1 *}$ and Dayanand A Bhiwgade ${ }^{2}$ \\ ${ }^{1}$ Department of Life Sciences, University of Mumbai, Kalina, Santacruz (E) 400098, Mumbai, India \\ ${ }^{2}$ Department of Biological Sciences, D. Y. Patil University, Belapur, Navi Mumbai, India
}

\begin{abstract}
Background:Cisplatin is well-known anticancer drug often been used for treatment of various human malignancies. The hepatotoxic or nephrotoxic effect of drug is a result of altered histological and antioxidant status of the organ. In order to document the extent of cisplatin (CDDP) effect on liver we have studied long term treatment of cisplatin (CDDP) to rat. In our previous studies we have demonstrated changes in reduced glutathione (GSH) and glutathione related enzymes of liver followed by increased lipid peroxidation process.
\end{abstract}

Materials: Light microscopy (LM) was carried out in liver tissue by haematoxylin and eosin staining. Electron microscopy was performed by staining with uranil acetate and lead citrate.

Results: Recent reports depicts that CDDP treatment caused significant alteration at histopathological level showing increased vacuolation in hepatocytes. A noticeable change observed after drug treatment is large perilobular connective and expanded portal spaces. Morphological alterations after transmission electron microscopy (TEM) showed heterochromatic border in nucleus followed by prescence of large agglutinations of lysosomes, numerous rough endoplasmic reticulum (RER) and mitochondria has been observed as one of the significant effect of drug.

Conclusion: Thus cytoarchitectural studies signify that long term of CDDP intervention at $0.4 \mathrm{mg} / \mathrm{kg} /$ day/animal caused least damage to liver.

Keywords: CDDP; Histopathological; Hepatocytes; Rough endoplasmic reticulum; Mitochondria

\section{Introduction}

CDDP is a planer-molecule that contain a central platinum atom surrounded by two chloride atoms in Cis-configuration and two ammonium moieties. CDDP is found to be inactive in its parent form and requires to undergo aquation/hydroxylation reaction to form potentially activated species [1]. The dissociation of chloride ions from platinum at low salt concentration equivalent to the intracellular concentration of chloride creates a electrophilic form of platinum which binds to cellular nucleophiles such as DNA, RNA and negatively charged proteins [2].

Liver is known to be primary site were most of metabolic reactions takes place. Anticancer drugs such as CDDP, doxorubicin, etoposide etc are also biotranformed in liver by drug metabolizing enzymes Cytochrome p450 [3,4]. CDDP also interact with reduced glutathione and form Cis-GSH conjugates which has been reported to be responsible nephrotoxicant [5]. However studies on damaging effect of CDDP to liver have paid scant attention.

In our previous studies we have reported the mechanism of action of CDDP and enzymes that are involved in its bioactivation process. We have also reported that long term administration of the drug can alter most antioxidant enzymes and increase oxidative stress indicated by incresaed lipid peroxidation level in animals [3].

Based on our previous studies we have attempted to study the histopathological and ultrastructural alteration of hepatic tissue after cisplatin treatment.

\section{Material and Methods}

Adult male albino rats of Wistar strain were obtained from
Rajudyog Biotechnology division India were used for the study. Studies on animals were approved from institutional animal ethics committee.

Rats were maintained in optimal condition and received standard pellets and water ad libitum. The animals were acclimatized for a period of 2 weeks and were then treated. They were coded in the group of two per cage and then subsequently examined for further study. Experimental rats were divided into two groups. Group 1 was injected with $0.4 \mathrm{mg} / \mathrm{kg}$ of CDDP i.p. daily, for a period of 8 weeks. Control group received $0.5 \mathrm{ml}$ of saline i.p daily along with the treated set of the rats. The change in the body weight was monitored per week. At the end of the treatment, rats were given light ether anesthesia and sacrificed. Liver was perfused and rapidly removed for both histopathological and ultrastructural studies.

\section{Structural studies}

Light microscopy: The histological changes of liver by light microscopy was studied by using paraffin method as described earlier [6]. Liver tissue was cut into pieces of desired size and fixed into Bouin's fixative (saturated picric acid $75 \mathrm{ml}+$ conc. Formalin $25 \mathrm{ml}+$ glacial acetic acid $5 \mathrm{ml}$ ) for 24-48 hrs. Tissues were removed from fixative

*Corresponding author: Pratibha R.Kamble, 17B, Kaupineshwar, Chendan Koliwada, Natu Paranjpee Colony, Near Siddhivinayak Mandir, Thane (East) 4000603, India, E-mail: pratibharavindran777@gmail.com

Received August 16, 2011; Accepted October 17, 2011; Published October 21 2011

Citation: Kamble PR, Bhiwgade DA (2011) Cisplatin Induced Histological and Ultrastructural Alterations In Liver Tissue of Rat. J Cytol Histol 2:128. doi:10.4172/2157-7099.1000128

Copyright: (c) 2011 Kamble PR, et al. This is an open-access article distributed under the terms of the Creative Commons Attribution License, which permits unrestricted use, distribution, and reproduction in any medium, provided the original author and source are credited. 
Citation: Kamble PR, Bhiwgade DA (2011) Cisplatin Induced Histological and Ultrastructural Alterations In Liver Tissue of Rat. J Cytol Histol 2:128. doi:10.4172/2157-7099.1000128

solution and washed thoroughly with distilled water for few hours so as to remove extra Bouin's fixative.

After fixation, samples were washed with $70 \%$ alcohol to remove excess of picric acid from the tissues and dehydrated in graded series of ethanol. Liver biopsies were dehydrated in ascending grades of molten paraplast $58-62 \mathrm{C}$. Three $\mu \mathrm{m}$ thick histological sections were cut and stained with hematoxylin and eosin and examined under bright field light microscope.

Transmission electron microscopy: Liver were removed from the animals instantaneously to their been anesthesized and killed by decapitation, sliced into one $\mathrm{mm}$ pieces in a drop of $3 \%$ glutareldehyde. Tissue was then immersed in fresh ice cold fixative for two hours and then in $0.1 \mathrm{M}$ cacodylate buffer for next $4 \mathrm{~h}$. The tissues was then rinsed briefly in buffer and post osmicated in $1 \%$ osmic acid for one to two hours.

Liver was dehydrated in an ascending series of alcohol, followed by propylene oxide and finally embedded in resin that was polymerized at $600^{\circ} \mathrm{C}$. Subsequently the blocks were prepared in araldite and $1 \mathrm{~m}$ sections were cut with a glass knife on LKB-2000S, ultramicrotome mounted on glass slides and stained with buffered toluidine blue. Appropriate areas were selected with the light microscope. Finally, ultra thin sections of selected blocks were cut with a diamond knife, picked up on copper grids and stained with uranil acetate and lead citrate for final viewing. The ultra thin sections were scanned and photographed on JEM-JEOL 100s electron microscope. Magnification used to observe the sectioned tissue was $(\mathrm{x} 10,000)$.

\section{Results}

\section{Body weight}

The weekly changes in body weight in 8 weeks controls and
Cisplatin treated rats shown in Table 1. Cisplatin treated group showed decreae in body weight as compared to control set of rats.

\section{Light microscopy of liver}

Light Microscopic studies of liver after CDDP treatment revealed the damage to parenchyma tissue of liver. Large vacuolations in the perinucleus region was also observed (Figure 1). Perilobular connective appeared larger than normal and portal spaces were expanded (Figure 2). Almost all the hepatocytes showed abnormal vacuolations and irregular morphology. Although few of hepatocytes still appeared normal (Figure 1).

\section{Electron microscopy of liver}

Electron Microscopy of liver after CDDP treatment, appeared highly activated for detoxification activity (Figure 3). The heterochromatin condensation along the nuclear margin, small but prominent nucleolus along the nuclear envelop (Figure 4) was noticeable feature of the hepatic cells. Cellular margins were showing rough and irregular contours. Many free arrays of RER were observed (Figure 4 and 5). Mitochondria in particular were many, ranging from small round to long rod like shape. Their matrix appeared dense and perforated at times (Figure 4) larger lysosomes were some of the observable features (Figure 3), which resulted into cell shrinkage. The sinusoidal spaces appeared dilated, but microvilli appeared intact and tubular (Figure 5). Abundant distribution of small and free vesicular cisternae of SER was also noticed (Figure 3).

\section{Discussion}

CDDP exhibits a remarkable feature in cancer chemotherapy and it is used extensively in clinical trials. The mechanism of action of the drug involves formation of hydroxylated/acquated species, that

\begin{tabular}{|c|c|c|c|c|c|c|c|c|}
\hline Subjects & & & & Weeks & & & & \\
\hline & I & II & III & IV & V & VI & VII & VIII \\
\hline & & & & & & & & \\
\hline CONTROL & $300 \pm 3.1$ & $312 \pm 3.7$ & $324 \pm 7.8$ & $334 \pm 11.4$ & $349 \pm 13.8$ & $355 \pm 13.8$ & $365 \pm 13.4$ & 36712.3 \\
\hline & & & & & & & & \\
\hline CISPLATIN & $238 \pm 5.8$ & $239 \pm 10.9$ & $184 \pm 23.0$ & $191 \pm 17.2$ & $192 \pm 19.6$ & $190 \pm 19.5$ & $204 \pm 6.2$ & $208 \pm 8.4$ \\
\hline
\end{tabular}

Table 1: The weekly Changes in the body weight of 8 weeks Control and Cisplatin treated male rat.

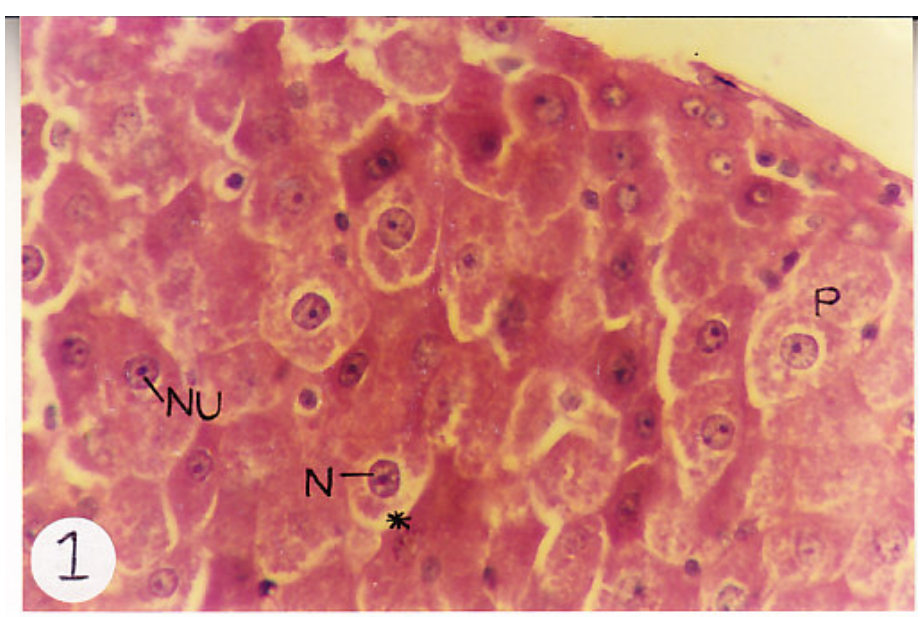

Figure 1: Morphology. 
Citation: Kamble PR, Bhiwgade DA (2011) Cisplatin Induced Histological and Ultrastructural Alterations In Liver Tissue of Rat. J Cytol Histol 2:128. doi:10.4172/2157-7099.1000128

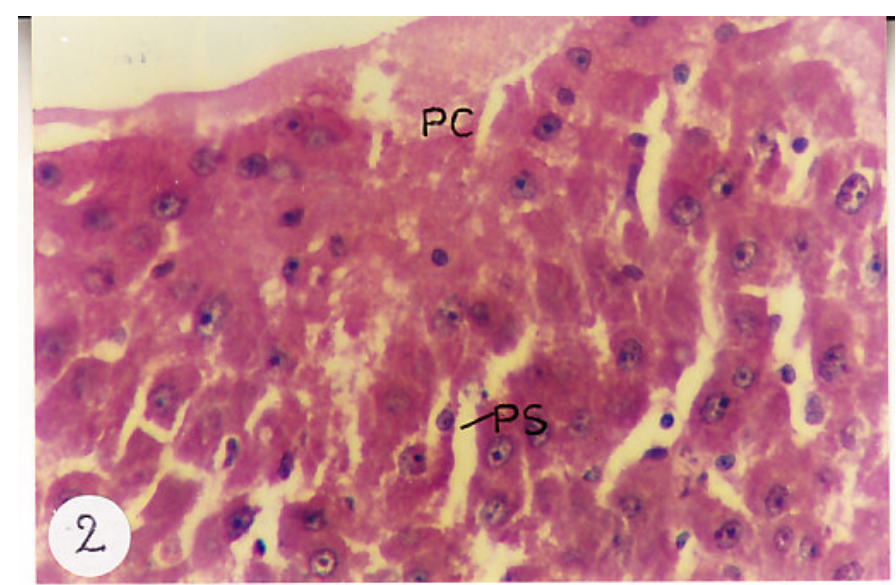

Figure 2: Light Micrographs of rat liver treated with Cisplatin for 8 weeks shows large perilobular connective (PC). Also observe the expanded portal spaces (PS). The photos are taken at the magnification (x 20).

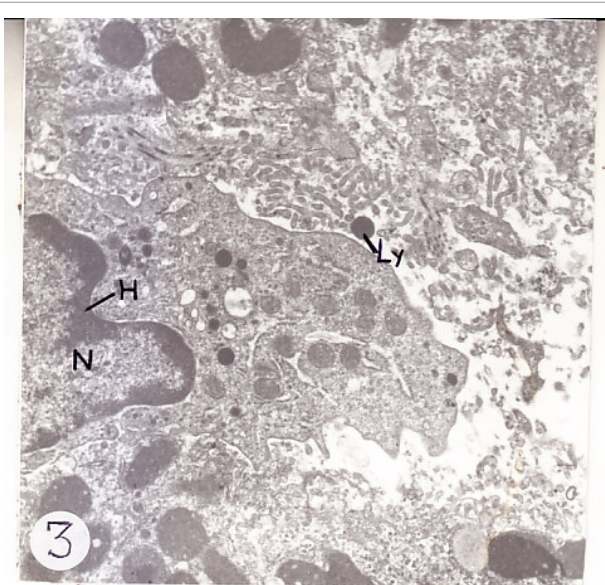

Figure 3: Electron micrographs of rat liver treated with Cisplatin for 8 weeks shows following features of nucleus $(\mathrm{N})$ with heterochromatic border $(\mathrm{H})$. Figures also shows prescence of large agglutinations of lysosomes (Ly).

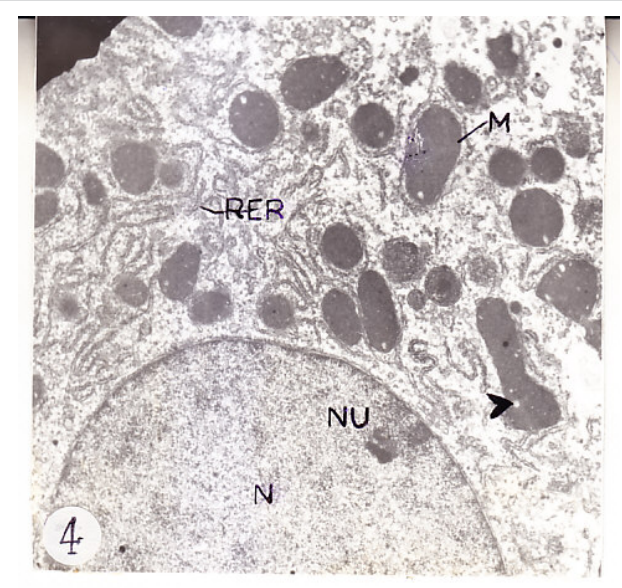

Figure 4: Electron Micrographs of rat liver shows.

reacts with various biological molecules [5,7]. CDDP inhibits various enzymes, the mechanism includes the interaction of the drug with sulfhydryl groups [8].
Due to long term side effects the application of the drug is limited in medical oncology [9]. However the dose dependent toxic effects of the drug remains matter of great concern that needs to be addressed. 


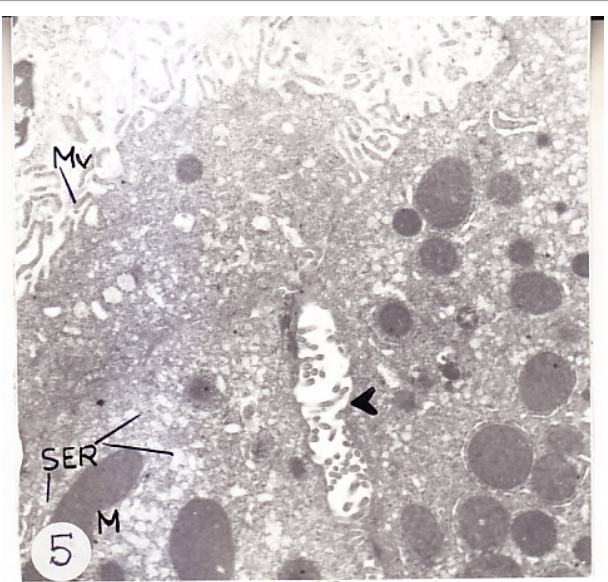

Figure 5: Electron micrographs of rat liver treated with Cisplatin for 8 weeks shows following features shows the prescence of dilated sinusoidal spaces (arrow head) and intact and tubular microvilli (Mv). Small rounded cisternae of smooth endoplasmic reticulum (SER) are also seen. Elongated mitochondria are also seen. The photos are taken at the magnification (x 10,000).

Therefore it is felt to analyze the extent of liver damage after drug treatment. We have documented essential correlation between hepatic histological, Ultrastructural and biochemical status in order to better understand the effect of drug regimen on pathology and metabolism of rat.

In our previous studies we have reported that CDDP at $0.4 \mathrm{mg} / \mathrm{kg}$ i.p for period of 8 weeks showed no significant changes in antioxidant enzymes however, the levels of lipid peroxidation showed significant increase followed with lowered glutathione levels [3].

Cytochrome p450 which is drug metabolizing enzyme showed significant increase documenting that the enzyme has major role in biotransformation reactions [3].

Present studies we have attempted to support the findings with histopathological and morphological changes. Our histopathological investigations showed damage to parenchymal tissue accompanied by large vacuolations around the nucleus, which is indicative of drug effect. The perilobular connective appeared to be larger than normal and portal spaces were expanded. The hepatocytes showed abnormal vacuolations indicative of irregular morphology whereas, some of hepatocytes were seen to be still normal.

Electron microscopic studies showed that liver tissue after CDDP treatment appears to be highly activated due to detoxification activity which is one of important function of liver. The heterochromatin condensation along the nucleolar margin and small but prominat nucleous along the nucleolar envelop were one of the noticeable features observed in hepatic tissue. Cellular margins showed rough and irregular counters, many arrays of rough RER were also observed. Mitochondrial number in particular of CDDP treated liver were many, ranging from small round to long rod shaped. There matrix appeared dense and perforated at times. Therefore, mitochondrial heterogenesity observed within a cell might be a regulatory response of the organelle to the energetics or nutritional state of cell [10].

Futher it can be stated that as glutathione is synthesized in mitochondria, thus increased numbers of mitochondria may be to decrease the cytotoxic action of drug [5].

Our finding runs parallel with previous reports which states that an experimental biliary obstruction in rat with large number of relatively small, rounded mitochondria with increased number of SER is a clear indication of detoxifying enzymatic mechanism which occurs due to long- term accumulation of drug [11].

Kharbangar et al. [5] reported that mitochondrial dysfunction could be major mechanism of drug-induced liver disease. Investigators have also reported that possible unusual hyperpolarisation of mitochondria in hepatic cells may prove that it is intimately related to energy patterns. Also that it builds up a electrochemical membrane gradiant, without been able to extract the potential energy in usual manner [12]. Thus role of reactive oxygen species and hydroxyl radical certainly be expected at this stage of study. Cellular structure provides us with a hint that mitochondria might be one of the targets of potency in CDDP-mediated cancer chemotherapy and toxicity.

\section{Acknowledgement}

We would express our sincere thanks to all members of the lab. Our special thanks to all team of Jaslok hospital and Research Center Dr. Arun Chitale, Mr. Kanaskar, Mr. Shivaji Bhosale and Mr. Mahadik for their assistance with the electron microscopic work.

\section{References}

1. Rosenberg B, Vancamp L, Krigas T (1965) Inhibition of cell division in Escherichia coli by electrolysis products from a platinum electrode. Nature 205: 698-699.

2. Goldstein RS, Mayor GH (1982) Minireview. The nephrotoxocity of cisplatin Life Sci 32: 685-690.

3. Pratibha R, Sameer R, Rataboli PV, Bhiwgade DA, Dhume CY (2006) Enzymatic studies of cisplatin induced oxidative stress in hepatic tissue of rats. Eur J Pharmacol 532: 290-293.

4. Liu H, Baliga R (2000) Effect of iron chelator, hydroxyl radical scavenger and cytochrome P 450 inhibitors on the cytotoxicity of cisplatin to tumour cells. Anticancer Res 20: 4547-4550.

5. Kharbangar A, Khynriam D, Prasad SB (2000) Effect of cisplatin on mitochondrial protein, glutathione and succinate dehydrogenase in Daltonlymphoma-bearing mice. Cell Biol Toxicol 16: 363-373.

6. Humason, Gretchen L (1979) Animal tissue techniques, WH Freema and Co San Franciso.

7. Aull JL, Allen RL, Bapat AR, Daron HH, Friedman ME, et al. (1979) The effects of platinum complexes on seven enzymes. Biochim Biophys Acta 571 352-358.

8. Litterst CL, Tong S, Hirokata Y, Siddik ZH (1983) Stimulation of microsomal drug oxidation in liver and kidney of rats treated with the oncolytic agent cis- 
Citation: Kamble PR, Bhiwgade DA (2011) Cisplatin Induced Histological and Ultrastructural Alterations In Liver Tissue of Rat. J Cytol Histol 2:128. doi:10.4172/2157-7099.1000128

Page 5 of 5

dichloro-diammineplatinum-II. Pharmacology 26: 46-53.

9. Antonio Z, Cafaggi S, Mariggi MA, Vannozzi MO, Bocchini MV, et al. (2002) Reduction of cisplatin hepatotoxicity by procainamide hydrochloride in rats. Eur J Pharmacol 442: 265-272.

10. Lash LH, Visarius TM, Sall JM, Qian M, Tokarz JJ (1998) Cellular and subcellular heterogeneity of glutathione metabolism and transport in rat kidney cells. Toxicology 130: 1-15
11. Narayane $V(2002) \mathrm{CPA}+\mathrm{TE}$ combination regimen and ultrastructure of pituatary gland in some mammals.Ph.D thesis, Unversity of Mumbai.

12. Leist M, Single B, Csatoldi AF, Kuhnle S, Nicotera P (1997) Intracellular adenosine triphosphate (ATP) concentration : a switch in the decision between apoptosis and necrosis. J Exp Med 185: 1481-1486. 